\title{
Gatekeepers Practices in Knowledge Diffusion within Saudi Organizations: KFMC Case Study
}

\author{
Mona Alawadh, Abdullah Altameem \\ Information Systems Department (IS) \\ Al Imam Mohammad Ibn Saud Islamic University (IMSIU) \\ Riyadh, Saudi Arabia
}

\begin{abstract}
Gatekeepers in organizations play a critical role in terms of disseminating and transferring outside knowledge into their groups. This research contributes in identifying the gatekeepers' practices in terms of gathering, selecting, and diffusing knowledge. In the context of Saudi organizations, the exploratory case selected in this research is King Fahad Medical City (KFMC). This research is conducted on Health Informatics and Information Technology employees. A mixed-method design is applied on this research to provide a deep understanding of knowledge interactions structure and the process of knowledge interactions across the organization network. Both methods; questionnaires and interviews are conducted in order to investigate the context. Social Network Analysis method is also used in this research to capture the "brokerage" network structure position using Flow Betweenness Centrality algorithm. The findings reveal that gatekeepers use different knowledge sharing mechanisms which are: information retrieval, information pooling, pushing, diffusion, collaborative problem solving, and thinking along. In addition, the results present the distinct methods and technologies used by the gatekeepers to collect and share their knowledge with others. The findings of this research help managerial decision makers and strategic managers among start-up organizations and also well-structured organizations to provide valuable insights and decisions in terms of policies, strategies, and the appropriate collaborative tools that foster collaborative working.
\end{abstract}

Keywords-Knowledge sharing; gatekeepers; brokerage; knowledge transfer; and SNA

\section{INTRODUCTION}

Organizations viewed knowledge as a significant strategic resource because it represents the core of organizational learning, managerial cognition, and the management of technology [1]. Knowledge could be embedded in the organization' s identity and culture, policies, routines, systems, and documents, as well as the employees of the organization [2]. Nonaka defined the term "Knowledge" as;

"Dynamic human process of justifying personal believes as part of an aspiration for the truth." [3]. Managing knowledge in organizations is important for organizational innovation [4][5]. This research focuses on the informal knowledge interactions on virtual communication tools within the organization. In particular, informal interactions in the organization network cause "weak ties" between teams, groups, units, and divisions which affecting transferring knowledge among the organization [2][6]. As informal networks affect the working life in organizations [7], studying the informal networks in organizations can clarify the structural gaps and led to have a good insight for successfully constructing formalized networks [8]. It is important to mention that informal knowledge and information exchange routes developed based on the local needs of the organization [9]. Weak ties or weak connections in the organization network represent structural holes in the network structure [9][10][11]. The existence of structural holes in the organization network doesn' $t$ mean that there is a gap in knowledge and information flow between two groups or clusters, but it means an area of weak connections [12]. Creating a link to bridge the gap in the network structure in order to connect those groups is called "brokerage" connection [9]. In the context of organization network structure, employees on the "brokerage" position can play different roles based on knowledge flow between and within different groups: Gatekeeper, Coordinator, Liaison, Representative, or Itinerant broker [13]. Tushman defined Gatekeepers as; "Individuals in the communication network who are capable of understanding and translating contrasting coding schemes." [14]. Capturing the gatekeeper employees is very important because gatekeepers are professionally oriented, technical performers, overrepresented at lower levels of the organizational hierarchy, and they are not formally recognized by the organization [15]. Also, highlighting their practices in knowledge diffusion gives an insight of the best practices in disseminating knowledge across groups within the organizations [16]. Studies mentioned that individuals on the "brokerage" network structure position have the capacity to ease social interactions and information flow, and dismissing knowledge among connections [6][9][12]. Moving to Saudi organizations context, the limited local researches captured the fact that local organizations are still in the stage of understanding the environment requirements (challenges, opportunities, and taxonomies) in the knowledge management (KM) field [17][18][19][20][21][22][23][24][25]. However, the researchers in this study capture gatekeeper employees in King Fahad Medical City (KFMC) using social network analysis (SNA) method. Additionally, they conduct indepth interviews with the gatekeepers in order to understand the combined views of the structure and the process of knowledge sharing (KS) among groups' knowledge interaction network. The findings of this study introduce gatekeepers' practices in knowledge collection and it capture gatekeepers' KS mechanisms, which are assisting the decision makers in the organizations in terms of policy, decision, and behavior creation. 
The rest of this paper is organized as the following: the second section presents the literature review by introducing the main concepts related to this research. A brief description of the selected case of this research, pilot study, data collection and analysis are included in the Research Methodology section. The Results and Discussion section introduces the qualitative and quantitative results and it provides critical analysis of the research results from different aspects. The conclusion of this research is covered in the last section.

\section{LITERATURE REVIEW}

The theme of the literature review of this research is related to three research directions which are: Knowledge Sharing, Social Capital, and Gatekeepers.

\section{A. Knowledge Sharing}

There are three major processes in the integrated cycle of KM that support managing knowledge in organizations which are: Knowledge Capture and/or Creation, Knowledge Sharing and Dissemination, and Knowledge Acquisition (KA) [26]. Knowledge Sharing and Dissemination which means provide or receipt information, know-how, and feedback regard something [27]. Gatekeepers could use the KS mechanisms for transferring knowledge with others. KS mechanisms such as [28]:

- Diffusion: storing the information on intranet to be accessible by others.

- Information retrieval: means that the content of the shared knowledge is associated with transferring factual information.

- Information pooling: concerns about questions, suggestions, and instructions not only consist of transferring factual information.

- Collaborative problem solving: consists of developing new information related to a shared problem. This mechanism associated with suggestions, new ideas, and questions.

- Pushing: try to provide some knowledge without asking your assist.

- Thinking along: means thinking about opportunities in group meetings or developing ideas for someone else's problem.

- Self-suggestion: means thinking about someone's own problem during the interaction.

The following section provides more details in order to understand knowledge flow and interactions between the members.

\section{B. Social Capital}

Social capital is a core concept in organizational behavior, business, political science and sociology [29]. Nahapiet defined Social capital as; "The sum of the actual and potential resources embedded within, available through, and derived from the network of relationships possessed by an individual or social unit." [30]. The concept of social capital used in organizations to explain the role of relational resources involved in social network relationships [31]. The term "Society Network" means activists of society and the aggregation of the relations between social elements. Aggregation is composed of number of points and lines connected together. Points in the network could be individuals, companies, units, cities and countries, etc. [32]. The social network is a representation of the relations in society. In the same society, a number of social networks exist based on the type of the relations [33]. Social capital assists in knowledge creation and has positive effects on knowledge sharing among members of organizations [31][34]. for better understanding of the knowledge flow among the organization network, SNA is an innovative method that makes embedded relations in the organization social network visible to the key mangers [7][35][36]. SNA is; "The disciplined inquiry into the patterning of relations among social actors, as well as the patterning of relationships among actors at different levels of analysis. " [37]. Moreover, Haythornthwaite pointed out the basic principles used in SNA to identify the relation properties between actors in the social network as the following [9]:

- Cohesion: Actors' grouping is based on strong common relations between them.

- Structural equivalence: Actors' grouping is based on similarity in relations.

- Brokerage: identifying the "bridging connection" actors to another network.

- Prominence: indicating the "accountable" or "in charge" actors.

- Range: indicating the span of actors' relations in the network.

This research focuses on "brokerage" network principle. This is because the power of the members on this network structure position in terms of facilitating the information flow and dismissing knowledge within connections [6][9][12]. Additionally, tighter and smaller networks can be less useful to their members than networks with weak ties to members outside of the main network [38]. However, brokerage measures are related to Betweenness centrality family. Betweenness centrality extend to which an individual lies between other individuals in the network. The measure reflects the number of individual actors connected indirectly through their direct links [38][39][40]. In such cases, an individual can be a "Gatekeeper" who has a potential control over others.

\section{Gatekeepers}

Gatekeepers is identified as individuals who are both strongly connected to internal colleagues and strongly linked to external domains [13][14][41]. Gatekeepers play a major role in information control and knowledge gathering and diffusion into their groups [14][16][42]. Evidence suggests that gatekeepers do more than mediate external information; they facilitate effective communication for their groups within the organization and provide potential paths to outside world $[14][41][43]$. Moreover, gatekeepers in the organizations contribute to the organizational technical goals [41]; and they 
evolve to fulfil the need in which the formal organization is in capable to deal with [44]. In addition, there is no evidence of informal role of gatekeepers that may exist due to the formal organizational hierarchy [44]. Gatekeepers play different roles in the organizations which are based on the context. There are three situations of gatekeeper role which are [16][45]:

1) Monitoring: in situations where all collaborators have sufficient previous knowledge to grasp external information, as the external information related to ongoing activities, the role of the gatekeeper could be limited to environment monitoring.

2) Monitoring and translating: when the knowledge gap between individuals inside the organization and external actors is high, a gatekeeper is needed to monitor the environment and translate the technical information to be understandable to his/her group.

3) Centralizing: centralizing the interface with the environment may reduce organizational absorptive capacity; this happens when information flows are random.

Furthermore, gatekeepers, through their strategic position, affects organizational innovation levels positively [46], they reduce uncertainty situation [47]. External information, held by the gatekeepers, can be channelled within two-step process: First, the gatekeepers gather and understand outside information, and then they translate it into terms that are more meaningful to their groups [14][43][46]. Gatekeepers are responsible of the gatekeeping process. Gatekeeping process is not only filtering things but it is also making them more appeal to the final receiver [48]. Barzilai-Nahon suggests that network gatekeeping process is best conceptualized via information control, and it holds three main goals which are the following [15]:

1) “Locking-in" of gated inside the gatekeeper' $\mathrm{s}$ group network;

2) Protecting information, norms, gated, and subnets from unwanted entry from outside;

3) Maintaining ongoing activities within network boundaries without disturbances.

Gatekeeping is one of the three power mechanisms (gatekeeping, decoupling and resource allocation) which form the basis of a model of network power dynamics [49]. Gatekeeping itself has different bases; which are [15]:

1. Selection.

8. Manipulation.

2. Addition.

9. Repetition.

3. Withholding.

10. Timing.

4. Display.

11. Localization (including translation).

5. Channeling.

12. Deletion.

6. Shaping.

13. Integration.

7. Selection.

14. Disregard.

Moreover, studies in the literature mentioned the role of gatekeepers in transferring outside knowledge into their groups [15][50][51][52]. Social interactions foster close and intensive knowledge exchange [53][54]. Furthermore, Haas mentioned that identifying gatekeepers' practices that allow them to gather, select and diffuse outside knowledge and information into the organization is a future research direction [16]. Thus, the researchers attempt to identify the gatekeepers those controlling knowledge flow into their groups and capturing their practices in knowledge diffusion.

However, the following section provides a detailed description in terms of the methodology used in this study in order to capture the gatekeepers and their practices in knowledge diffusion.

\section{RESEARCH METHODOLOGY}

The methodology of this research is based on a single exploratory case study. The researchers follow the Deductive approach [55]. The exploratory case in this research is KFMC. KFMC belongs to the healthcare sector in Saudi Arabia. Selecting a single case for this research context is following the studies in [56][57]. A mixed-method design is used in this research for data collection and data analysis. The key members such as the researchers in the field and managerial decision makers are required to have "out-side" view which is related to the structure and "in-side" view which is related to the process in order to understand the context in depth [58]. Moreover, SNA method is used to understand the "out-side" view which is related to the knowledge flow across the organization network structure. On the other side, in order to interpret the "in-side" view which is related to the process, interviews are conducted in this study for deep understand of the context.

\section{A. Case Study}

$\mathrm{KFMC}$ is the selected organization to be the exploratory case organization in this research. KFMC is a critical case because it represents the Ministry of Health hospitals in Saudi Arabia. Also, it has number of achievements which reflect the power of their infrastructure on both IT and business sides. KFMC has eight hospitals and the organization structure of KFMC consists of fifteen administrations. In KFMC hospitals and administrations, there are around seven-thousand employees distributed there. The sample of this research is selected from the Administration of Health Informatics and Information Technology (HIIT). This is due to projects complexity and dynamic changes in the Information Technology (IT) sector which makes the context suitable for KS among KFMC employees. Another reason of selecting employees from Administration of HIIT, is because the IT background of the employees in this administration makes them aware of virtual communication tools. The Administration of HIIT has five main departments which are: IT Infrastructure Department, Customer Care Centre Department, Non-Clinical System Department, Clinical System Department, and Enterprise Architecture Department. The Customer Care Centre Department include two subdepartments which are: Telecommunication System Department and Technical Support Department. However, the research's institutional review board (IRB) is got from KFMC research center for official application of this research on KFMC employees. Additionally, regarding employees' confidentiality complains, the researchers use alias instead of participants' real names in this study.

\section{B. Pilot Study}

A pilot study is conducted in this research to make sure that there is no problem with the questionnaire instrument and to 
ensure that it is designed to work in an effective manner. The questionnaire of this study is evaluated by six experts who are interested in the Information Systems domain. The Telecommunication System Department is the selected group for the pilot study. In the Telecommunication System Department, there are nine employees who represent the total employees in the department. The questionnaire is sent to the employees' work emails by SurveyMonkey website. Email reminders are used to remind the employees who are not responding. After collecting the data, the data are exported to Excel sheets and processed. Then they are entered into the SPSS software to calculate internal reliability and internal validity measures using Cronbach's alpha score. This is to insure the consistency in scores and items homogeneity for the measured variables. The accepted score of Cronbach's alpha in general should be 0.70 or higher [59]. For the items in the questionnaire, Cronbach's alpha equals 0.926. Which means that this scale is accepted to measure the "brokerage" network structure position.

\section{Data Collection}

Semi-structured interviews are conducted face to face with five managers in the Administration of HIIT for fifteen minutes. This is to identify the collaborative tools used for inter-group communication, group context, and knowledge sharing environment in KFMC. However, the questionnaire of this research is built using five knowledge interactions ranking questions. This is to measure the employees' "brokerage" network structure position. The questions are derived from studies in [7][35]. The questionnaire of this research is sent to one-hundred-six employees in the five departments in HIIT using SurveyMonkey website with \% 68.8 response rates (seventy-three participants). It is important to highlight that the questionnaire of this research is targeting full groups which means all employees in the department have to participate rather than random individuals. This is because each department represents a population in this research. However, the collected data are cleaned by eliminating partial groups and dummy responses. For these reasons the response rate decreased into \% 33 response rates (thirty-five participants). The thirty-five employees are representing three full groups or departments in the Administration of HIIT:

1) Telecommunication System Department (nine employees).

2) Non-Clinical System Department (eleven employees).

3) Enterprise Architecture Department (fifteen employees).

Triangulation data collection is used in this research to increase the validity in this research results [59]. Moreover, in this research the data are collected within two rounds within one month. The first round is for Test and the second round is for Retest. The two rounds are separated by one week. The questionnaire is customized based on the employees in each department. For each department, the employees' names are presented in a list within each question. The respondent asked to rank the interactions with the employees based on his/her communication preference. As a result, the data collected in a form of Socio-matrixes, because the questions are related to social interactions domain. The sampling method used in this research is full social network, which means presenting all the actors names in the network in a list to the respondent to overcame the bias of free recall (snowball). After conducting the questionnaire, face to face semi-structured interviews for fifty to sixty minutes are conducted with the employees on the "brokerage" network structure position. The interview questions are derived from the studies in [27][60]. The interview questions investigate the gatekeeping bases, the technologies used for sharing documents, practices of collecting the knowledge, knowledge sharing mechanisms, and initiative and couching characteristics. Also, the interviewer checks some archival documents to increase the research results validity. Furthermore, the reason of checking the gatekeeping bases is to make sure that the selected employees acting as gatekeepers. Therefore, the interviewer investigates his/her practices in collecting and disseminating knowledge.

\section{Data Analysis}

Mixed- method analysis is used to analyze the data in this research. The data are analyzed qualitatively and quantitatively respectively. For the quantitative analysis UCINET 6 software is used in order to analyze the Socio-matrixes. Flow Betweenness Centrality algorithm is used to measure the "brokerage" network structure position. The reason of selecting this measure over other measures in the Betweennees centrality family is that measure focuses on the information flow rather than the brokerage only [61]. However, for each department there will be five Socio-matrixes which are representing the knowledge interaction relations. The Mean of Flow Betweenness Centrality is calculated for each employee in the department. The employee with the highest Mean is selected to be on the "brokerage" network position. In this research, fifteen Socio-matrixes are analyzed for the three departments those are participated in the questionnaires. Moving to the qualitative analysis, content analysis type is used to analyze the interviews data in this study [55]. Moreover, secondary data such as archival documents are checked and they were helpful in supporting the data interpretation for the validity of the research results.

\section{RESULTS AND DISCUSSION}

From the pre-interviews that are conducted at the early stage of this research, the researchers get a general view of KFMC knowledge sharing environment as well as they get a view of the tools used for work collaboration. The HIIT top management in KFMC gives attention of knowledge codification and diffusion, as the chairman of Enterprise Architecture Department states; "The top management organized a competition between the employees. The competition is based on how many technical notes an employee can create per year". Also, they support the knowledge sharing environment by conducting seminars and conferences, as the IT Infrastructure Department chairman declares; "Yes, KFMC supports the knowledge sharing environment by conducting seminars and conferences". The top management, also, gives attention of building knowledge database, as the Technical Support manager says; "There is a library, yet, not activated for some issues". The departments in KFMC use different tools for inter-group communication and work collaboration, such as: SharePoint, Outlook, Lync, What'sApp, text messages. The chairman of Enterprise Architecture Department says; "For 
group communication, we use SharePoint to achieve work integration. Emails, Lync and What'sApp are used, also, for communication and ideas sharing $\cdots$ What'sApp is easier than Lync". The chairman of Non-Clinical System Department explains the reason of using What'sApp in inter-group communication; "*..for example, SharePoint is used for managing documents, Outlook is remarkably used for work documentation through emails $\cdots$ text messages $\cdots$ What'sApp especially for standby on critical tasks as it is easy to be set on devices, and it is handy. We use Lync but it is not easy to be set on different devices types of different version".

However, the results of this research are presented for Telecommunication System Department, Non-Clinical System Department, and Enterprise Architecture Department.

\section{A. Telecommunication System Department Results}

1) Brokerage results: The Mean of the Flow Betweenness Centrality of the five Socio-matrixes of knowledge interactions is calculated.

As presented in Fig.1, Hashim has got the Max Mean of Flow Betweenness Centrality which equals 13.0666. This means that Hashim on the "brokerage" network structure position. However, an interview is conducted with Hashim in order to investigate how do gatekeepers gather, select, and diffuse outside information and knowledge into their groups in the organization.

2) Interview results: The interview results organized in the following parts.

a) Gatekeeping Bases: Hashim analyzes and shapes his knowledge using flow charts to make it understandable. Hashim says; "I prepare presentation materials when required...I use flowcharts for explaining the information". Based on the current context of Hashim's team, there is no need for translating, filtering, and deleting any part of the sent knowledge. he explains; "There is no need for different translations of the information to make them understandable because my colleagues understand what I send... There is no need to filter the sent information or delete the unnecessary information because I know my colleague understand the purpose of the information". In addition, Hashim selects the suitable time and the suitable person for providing the knowledge and repeating the sent knowledge verbally. He states; "I try to select the suitable moments for providing ideas. I try to select the suitable person to make sure that the idea will not delay the current tasks...I send the information to the suitable person. I use email reminders to remind myself to send this information once this person is available...I do not re-send the information to the same receiver, but I may talk about it again face to face".

\begin{tabular}{|llllllll|}
\hline Empl & KI1 & KI2 & KI3 & KI4 & KI5 & Sum & Mean \\
\hdashline Samar & 8.55 & 7.783 & 7.383 & 8.55 & 8.95 & 41.216 & 8.2432 \\
Khaled & 9.533 & 9.55 & 10.95 & 10.95 & 8.2 & 49.183 & 9.8366 \\
Shatha & 8.8 & 5.7 & 8.8 & 8.8 & 13.2 & 45.3 & 9.06 \\
Faris & 8.8 & 7.033 & 7.633 & 9.55 & 8.95 & 41.966 & 8.3932 \\
Basem & 3.133 & 3.133 & 3.133 & 0.8 & 0 & 10.199 & 2.0398 \\
Semon & 4.3 & 2 & 3.3 & 3.3 & 5.5 & 18.4 & 3.68 \\
Arfan & 3.5 & 1.45 & 3.5 & 3.5 & 2.5 & 14.45 & 2.89 \\
Fadhel & 5.5 & 10.85 & 6.75 & 5.5 & 4.45 & 33.05 & 6.61 \\
Hashim & 14.433 & 16.35 & 15.6 & 13.6 & 5.35 & 65.333 & 13.0666 \\
\hline
\end{tabular}

Fig. 1. Mean of Flow Betweenness Centrality of Telecommunication System Department Employees

b) Technology and Knowledge Collection Practices: Hashim is a 13years-work-experience staff member. He collects his knowledge by professional internet searching, videos, self-development, filtering and codifying the knowledge using word documents. Then, he saves in a hard desk and private cloud in order to be accessible anywhere. Also, he marks some professional websites as favorite, and saves the important links in the email to be accessible anywhere, Thus, he has got a federated knowledge base; "I collect the information by internet searching, I couch myself, and I try to filter and write the collected information in a word documents, so I refer to them when needed...I send web links, screen shots for configuration, for example.... and videos from YouTube...I send the preferred links to my email, once I want to refer to them, it is easy from anywhere...also, I mark the important links as the favorite...I use Google drive to store my documents, to be accessible anywhere...regularly, I save my emails and documents every 6 months in a hard disk". Hashim mentions the need of chatting tool supported by photos attachment to support the virtual communication between the employees; "Photos facilitate understanding the technical problems, hence, when technical problems I send a photo to the technician, so the damage area is to be understandable".

c) Knowledge Sharing Mechanisms: Hashim uses information retrieval mechanism for knowledge sharing with his colleagues such as professional links, screen shots, and You tube videos to describe the confused information or to clarify concepts; "To clarify the confused information to my colleagues, I send web links, screen shots for configuration, for example.... and videos from YouTube". Regarding the 
information pooling, Hashim says; "Always, I give my suggestions and instructions but they are unnecessary to be applied because of financial issues, for example". For the collaborative problem solving, Hashim explains; "Yes, due to my 13 years of experience in KFMC, I know the place very well, once a problem occurs, there might be 2 conditions: the first condition, it could be a new problem. In this case, I google it and solve it. Then, I send the solution through the email. However, if I have had the issued problem, I take the technician to the spot and show him how to fix it". In addition, Hashim uses pushing mechanism for sharing his knowledge. He says; "I try to select the suitable person to make sure that the idea will not delay the current tasks...I send the information to the suitable person. I use email reminders to remind myself to send this information once this person is available". Also, he Thinking along his colleagues' work problems as his problem. Hashim says; "Yes, I try to solve my colleagues' work problem even if it is not of my duties, I try to do my best based on my knowledge, Also, I try searching to find the solution...I prepare presentation materials when required".

d) Initiative and Couching Characteristics: Hashim is an initiative taker and trainer by his nature. He says; "I consider myself as an initiative taker because I try to solve my colleagues' work problem even if it is not of my duties when necessary...When a new technician, whom I feel is not understanding any work issue, is applied to the work, I specify part of my time training and couching him in the spot, or I might, sometimes, train him in the office during the working hours...even if nobody is asking for assistance". The Telecommunication system manager declares; "Hashim is interested in learning, doer, and overall cooperative person...He is the top in my team".

\section{B. Non-Clinical System Department Results}

1) Brokerage results: The Mean of the Flow Betweenness Centrality of the five Socio-matrixes of knowledge interactions is calculated.

As presented in Fig.2, Noura has got the Max Mean of Flow Betweenness Centrality which equals 14.4432. This means that Noura on the "brokerage" network structure position. The following section presents Noura's interview results.

\begin{tabular}{|llllllll|}
\hline Empl & KI1 & KI2 & KI3 & KI4 & KI5 & Sum & Mean \\
\hdashline$--e--1$ & 6.033 & 8.667 & 7 & 10.633 & 12.467 & 44.8 & 8.96 \\
Reem & 13.15 & 10.75 & 13.317 & 15.067 & 11.267 & 63.551 & 12.7102 \\
Rasha & 13.53 \\
Talal & 10.533 & 8 & 12.783 & 8.2 & 18.167 & 57.683 & 11.5366 \\
Ahmad & 14.933 & 9.617 & 11.817 & 13.533 & 13.433 & 63.333 & 12.6666 \\
Nawara & 8.817 & 5.6 & 5.633 & 8.133 & 6.533 & 34.716 & 6.9432 \\
Nouf & 11.7 & 7.167 & 9.617 & 9.2 & 8.767 & 46.451 & 9.2902 \\
Basmah & 7.183 & 7.033 & 7.85 & 6.667 & 6.7 & 35.433 & 7.0866 \\
Sahar & 4.767 & 7.8 & 4.733 & 5.333 & 6.3 & 28.933 & 5.7866 \\
Maisa & 5.117 & 6.85 & 5.617 & 0 & 3.3 & 20.884 & 4.1768 \\
Noura & 11.733 & 26.5 & 13.617 & 9.033 & 11.333 & 72.216 & 14.4432 \\
Anas & 8.067 & 15.95 & 11.283 & 12.733 & 10.567 & 58.6 & 11.72 \\
\hline
\end{tabular}

Fig. 2. Mean of Flow Betweenness Centrality of Non-Clinical System Department Employees

2) Interview results: The interview results organized in the following parts.

a) Gatekeeping Bases: Noura analyzes and shapes her knowledge using flow charts and steps to be understandable. Noura says; "I try to modify the code of the shared function to be understandable and I use flowcharts, steps to explain the provided information" -The interviewer asks her to provide a document of her work for the sake of checking-. Also, she translates and filters the sent knowledge. Noura explains; "Yes, I translate the new concept to a concept that my team is familiar with, or I try to match the new concept with a common one...I try to summarize the shared information, for example, I summarize long paragraphs that contain additional information...I send web links, screen shots with a summary of information". Noura states that she does not delete unnecessary information; "No, I do not try to delete part of the information; once I want to share something, I have two choices: sending it as it is, or summarize it".

b) Technology and Knowledge Collection Practices: Noura is a staff member of about 2years work-experience. Noura collects her knowledge by internet professional searching, and blogs. She summarizes and codifies the collected knowledge in points using notebook. Noura scans the notes for sharing. She may write the points in a word 
document. Also, she marks some professional websites as favorite, and downloads resources to the PC from email. She says; "I collect the information by searching in the internet and blogs. If somebody sends me resources, I download it to my PC, and I try to summarize the information in points and write it in an external notebook. I scan the notes for sharing. If I have time I type these notes in a word document...I mark the favorite links".

\begin{tabular}{|c|c|c|c|c|c|c|c|}
\hline Empl & KI1 & KI2 & $\mathrm{KI} 3$ & KI4 & KIS & Sum & Mean \\
\hline Nafa & 21.654 & 14.375 & 13.923 & 17.789 & 18.732 & 86.473 & 17.2946 \\
\hline btisam & 10.643 & 16.642 & 13.077 & 11.202 & 9.982 & 61.546 & 12.3092 \\
\hline Najwa & 18.404 & 17.91 & 17.911 & 15.611 & 17.708 & 87.544 & 17.5088 \\
\hline Noura & 6.619 & 11.262 & 16.5 & 9.708 & 13.696 & 57.785 & 11.557 \\
\hline Rana & 19.679 & 20.261 & 15.429 & 17.421 & 22.601 & 95.391 & 19.0782 \\
\hline Ghady & 11.523 & 15.125 & 15.31 & 27.296 & 10.821 & 80.075 & 16.015 \\
\hline Fawza & 16.304 & 13.975 & 8.435 & 13.236 & 16.75 & 68.7 & 13.74 \\
\hline Fadia & 12.107 & 14.054 & 12.185 & 11.518 & 10.196 & 60.06 & 12.012 \\
\hline Aseel & 13.683 & 16.768 & 15.827 & 16.027 & 12.399 & 74.704 & 14.9408 \\
\hline Sara & 19.821 & 11.357 & 13.589 & 9.582 & 12.667 & 67.016 & 13.4032 \\
\hline Foz & 5.125 & 9.363 & 6.833 & 10.16 & 5.042 & 36.523 & 7.3046 \\
\hline Asma & 8.964 & 10.386 & 12.375 & 9.618 & 13.012 & 54.355 & 10.871 \\
\hline Hind & 14.036 & 13.274 & 13.262 & 13.671 & 12.506 & 66.749 & 13.3498 \\
\hline Aleen & 13.386 & 13.25 & 17.054 & 12.564 & 15.958 & 72.212 & 14.4424 \\
\hline Nouf & 3.286 & 8.071 & 4.792 & 3.917 & 2.679 & 22.745 & 4.549 \\
\hline
\end{tabular}

Fig. 3. Mean of Flow Betweenness Centrality of Enterprise Architecture Deparment Employees

c) Knowledge Sharing Mechanisms: SharePoint as intranet which is mainly used by Non-Clinical System members for sharing knowledge, as the team manager says; "...for example, SharePoint is used for managing documents". Therefore, for knowledge diffusion, Noura says; "I collect my work in a folder, then, upload it to the SharePoint server to be saved...I prefer SharePoint for sharing reports and documents. I like to use it because of file sharing and work integration properties...I use the DropBox for large documents". Also, she points out one disadvantage of the SharePoint searching feature; "It will be helpful if the search in the SharePoint is supported by categorization rather than searching all the files". Noura uses information retrieval mechanism for knowledge sharing with her colleagues such as professional links and screen shots to describe the confused information or to clarify concepts. She says; "I send web links, screen shots with a summary of information". Regarding the information pooling mechanism, Noura says; "I give my suggestions verbally in meetings". In addition, Noura uses collaborative problem solving mechanism in order to share her knowledge. She explains; "Yes, I give my idea face to face. If the others are interested, I send a reference by email, so, they have the ability to read and understand". Noura pushes her knowledge to her colleagues. Noura states; "Yes, once my colleague is talking about a work problem, I try to help her even if she is not asking for assistance". Moreover, Noura uses thinking along KS mechanism in order to share her knowledge. She says; "Yes, I try to solve my colleagues' work problem, I search about links and asking for others knowledge... I do my best until the problem is solved".

d) Initiative and Couching Characteristics: Noura is an initiative taker. Also, she tries couching her colleagues. She says; "I like helping others...Yes, once my colleague is talking about a work problem, I try to help her even if she is not asking for assistance...Y Yes, I try to solve my colleagues' work problem, I search about links and asking for others knowledge...I do my best until the problem is solved...once I learn something new, I try to coach my colleague in the office. I show her how I apply the new method...this is done during the working hours".

\section{Enterprise Architecture Department Results}

1) Brokerage results: The Mean of the Flow Betweenness Centrality of the five Socio-matrixes of knowledge interactions is calculated.

As presented in Fig.3, Rana has got the Max Mean of Flow Betweenness Centrality which equals 19.0782. This means that Rana on the "brokerage" network structure position. However, the following section presents Rana's interview results.

2) Interview results: The interview results organized in the following parts.

a) Gatekeeping Bases: Rana analyzes and shapes her knowledge using brief descriptions, flow charts, and infographics to make it understandable, she says; "If there is a specific flow for the shared information. I use flow charts or Infographics. I have to send something appeal and understandable... If there is a task, I write a brief description about the task with an infographic, if available, in addition to a source link". Moreover, she translates and filters the sent knowledge in regards to the recipient. Rana says; "Yes, I translate the sent information regarding the receiver. If the receiver is a manager, I never provide details, unlike if the receiver is a team member...Yes, I filter the things that are given by my manager. For example, if my manager sends me something related to work, I try to clarify some points, and add screen shots and steps. Therefore, when I send it to my team members they understand the requirements...For general resources, I share the resources regarding each team member interest...I send it through email, What'sApp, or Lync". Rana mentions that she is a time-selector when sending knowledge. Regarding repetitions, she is purpose-oriented based on the situation of the receiver. She says; "Yes, normally, referring to my (to do list), I decide what to do. I check my team's current tasks, therefore I do not send them things that make them confused or put them in conflict with their current tasks. It is important to choose the suitable time... If there is a need to resend the information for this person, I resend the information with a detailed description...I do not like duplication". Rana states that she is deleting unnecessary information; "Yes, when I select certain resources and then 
send them to my email, I integrate them with the list that I have previously, then I review all the resources in the list...I delete unnecessary ones due to the confusion that may made to my team...I share the list with my team after adding a brief description of each link".

b) Technology and Knowledge Collection Practices: Rana is a team leader in her group with 4years workexperience. She collects her knowledge by internet professional searching, blogs, videos, scientific papers, accessing online libraries such as iOS and Android libraries, and course training materials. Rana's searching method is based on "how to do?" things rather than "what to do?". She stores the scientific papers in her PC, saves web links in the email. She uses SharePoint and Dropbox for storing and sharing documents with her team and she marks professional links as favorite. Also, she summarizes and codifies her knowledge using videos, mind maps, infographics and flow charts in attractive ways. Rana says; "I collect the information by searching in google. I search different applications of ideas for visual feeding. I check different practices, then, picks up the best of them in application...Stackoverflow is helpful. Also, iOS and Android libraries...once I have a specific topic, I usually have a background supported by theories, due to my interest in scientific papers reference...I send course training links, articles, and videos... SharePoint is used for sharing the official reports and documents...SharePoint stores the documents for a long time. As a result, everybody has the ability to go through it anytime...I prefer using email, Dropbox for storing things because they are accessible anywhere...I mark the favorite links...I use iMindMap application for scoping the work -you can say (scope management)- and I share it with my team...I use ivideo application for designing videos to summarize the information which are presented. I prefer using videos specially in short time presentations for fast description...If there is a specific flow for the shared information. I use flow charts or Infographics. I have to send something appeal and understandable. I do my job with love" -The interviewer asks her to provide a document of her work for the sake of checking-.

c) Knowledge Sharing Mechanisms: SharePoint as intranet which is mainly used by Enterprise Architecture members for sharing knowledge, as the team manager says; "We use SharePoint for work integration". Therefore, for knowledge diffusion, Rana says; "I use SharePoint for documents sharing even if these documents are sent to the group emails". Also, Rana uses Dropbox for knowledge diffusion. She declares; "I use Dropbox for documents sharing with my team especially large documents... we do not utilize the SharePoint storage for large documents, but we should...The searching feature in Dropbox is good, whereas in SharePoint, it is good on the list level, but it does not give precise results on the site level". Rana uses information retrieval mechanism for knowledge sharing with her colleagues such as online articles, scientific papers, professional videos, and training courses links, to describe the confused information or clarify concepts. Rana explains; "Once I have a specific topic, I usually have a background supported by theories, due to my interest in scientific papers reference...I send course training links, articles, and videos...My help to my colleagues is based on the condition of the problem...I send an email with options supported by source links... Yes, usually, I provide steps supported by links and I send them by email". Regarding information pooling mechanism, Rana says; "Yes, usually, I provide steps supported by links and I send them by email...I send an email with options supported by source links". Moreover, for collaborative problem solving, Rana present her idea verbally in the workshops, and group meetings. Also, she sends emails to share her knowledge. She explains; "Yes, I present my ideas in workshops...I prepare presentations for my ideas...we discuss the idea verbally in the weekly meetings...I send an email with options supported by source links...In workshops, I use white board, colored sticky notes, highlighters, pens for preparing the ideas. Then, I do brain storming with my team to solve the problem. Each member writes a solution in the sticky note, then we discuss the suggested solutions". Rana pushes her knowledge verbally and using virtual communication tools such as emails, What'sApp, imessage, and Lync. She says; "Yes, I send links and online courses by email and What'sApp...I firstly provide solutions...My help to my colleagues is based on the condition of the problem. For major problems; if I have the knowledge I soon explain it either by visiting my colleague's office, by phone, What'sApp, Lync, or sometimes using imessages. However, for minor problems, I send an email with options supported by source links". Furthermore, Rana uses thinking along mechanism to share her ideas with her colleagues. Rana says; "Yes, Always I do, at the end we are working as a team. my team problems are mine...I do presentations for my ideas. For discussion, verbal communication is preferable".

d) Initiative and Couching Characteristics: Rana, is an initiative person. Also, she couches her colleagues. Rana states; "Absolutely I am an initiative person because I like being initiative in solving problems, and I proact in suggesting solutions...initiative is the reason behind my success...Yes, I normally teach. I send training course through email, and I do verbal communication during working hours. If my colleague is in need for training after the working hours, I never mind". The chairman of Enterprise Architecture Department says; "I consider Ghady, Foz, and Rana as initiative takers and proactive members in my team because they are cooperatives and they have the basic of sharing knowledge with others. They know this help them in their work". 
TABLE I. SUMMARY RESULTS OF GATEKEEPERS' INTERVIEWS

\begin{tabular}{|c|c|c|c|c|c|c|}
\hline $\begin{array}{c}\text { Participated } \\
\text { Groups }\end{array}$ & $\begin{array}{c}\text { Employees } \\
\text { with Max } \\
\text { Flow } \\
\text { Betweeness } \\
\text { Centrality } \\
\text { score } \\
\end{array}$ & $\begin{array}{c}\text { Gatekeeping } \\
\text { Bases }\end{array}$ & $\begin{array}{l}\text { Practices of } \\
\text { Knowledge } \\
\text { Collection }\end{array}$ & $\begin{array}{l}\text { Knowledge } \\
\text { Sharing } \\
\text { Mechanisms }\end{array}$ & Initiative & Coaching \\
\hline $\begin{array}{l}\text { Telecommuni } \\
\text { cation System } \\
\text { ( } 9 \text { members) }\end{array}$ & Hashim & $\begin{array}{l}\text { - Analyzing } \\
\text { - Shaping } \\
\text { - Timing } \\
\text { - Repetition }\end{array}$ & $\begin{array}{l}\text { - Professional } \\
\text { links searching } \\
\text { - Self-development } \\
\text { - Filtering and } \\
\text { codifying } \\
\text { knowledge }\end{array}$ & $\begin{array}{l}\text { - Information } \\
\text { retrieval } \\
\text { - Information } \\
\text { pooling } \\
\text { - Collaborative } \\
\text { problem solving } \\
\text { - Pushing } \\
\text { - Thinking along }\end{array}$ & yes & yes \\
\hline $\begin{array}{l}\text { Non-Clinical } \\
\text { System } \\
\text { (11 members) }\end{array}$ & Noura & $\begin{array}{l}\text { - Analyzing } \\
\text { - Shaping } \\
\text { - Manipulation } \\
\text { - Translating }\end{array}$ & $\begin{array}{l}\text { - Professional } \\
\text { links searching } \\
\text { - Summarizing and } \\
\text { codifying } \\
\text { knowledge }\end{array}$ & $\begin{array}{l}\text { - Diffusion } \\
\text { - Information } \\
\text { retrieval } \\
\text { - Information } \\
\text { pooling } \\
\text { - Collaborative } \\
\text { problem solving } \\
\text { - Pushing } \\
\text { - Thinking along }\end{array}$ & yes & yes \\
\hline $\begin{array}{l}\text { Enterprise } \\
\text { Architecture } \\
\text { (15 members) }\end{array}$ & Rana & $\begin{array}{l}\text { - Selection } \\
\text { - Analyzing } \\
\text { - Shaping } \\
\text { - Manipulation } \\
\text { - Translating } \\
\text { - Timing } \\
\text { - Repetition } \\
\text { - Display }\end{array}$ & $\begin{array}{l}\text { - Professional } \\
\text { links searching } \\
\text { - Course materials } \\
\text { - Scientific papers } \\
\text { - Summarizing and } \\
\text { codifying } \\
\text { knowledge }\end{array}$ & $\begin{array}{l}\text { - Diffusion } \\
\text { - Information } \\
\text { retrieval } \\
\text { - Information } \\
\text { pooling } \\
\text { - Collaborative } \\
\text { problem solving } \\
\text { - Pushing } \\
\text { - Thinking along }\end{array}$ & yes & yes \\
\hline
\end{tabular}

In order to have a single view of the interviews results, TABLE 1 summarizes the results. It presents each participated department results. for each department, the table captures the employee on the "brokerage" network structure position, the gatekeeping bases, practices of knowledge collection, KS mechanisms, and initiative and couching characteristic. The researchers observe that the selected employees on the "brokerage" network structure position are acting as gatekeepers. This is because they have gatekeeping bases such as (analyzing, display, shaping, timing, manipulation, repetition, selection, and translating) [15]. Furthermore, based on the interview results, the gatekeepers are using different KS mechanisms such as (diffusion, information retrieval, information pooling, collaborative problem solving, pushing, and thinking along) -which are depending on the context- in order to share their knowledge with their colleagues [28]. They collect and gather their knowledge using different ways based on their preference. They are searching professional links (e.g. blogs, videos, and websites), accessing course materials, reading scientific papers, and they filter, summarize, and codify the collected knowledge. Therefore, Gatekeepers use distinct methods and technology to serve their needs. They provide their knowledge in a way to be understandable and looking appeal [48]. However, the results capture the way that gatekeepers codify their knowledge. They are using videos, mind maps, info-graphics, steps, and flow charts in order to share their knowledge with others. Moreover, they store their knowledge using organization's intranet, external internet locations, and hardware storages. Gatekeepers also have initiative and couching characteristics. This is observed in their proactive and reactive attitudes in terms of assisting their colleagues in the work place.

On the other hand, the researchers observe that KFMC is an open environment that is adaptive to changes. KFMC supports KS environment, this is seen in their strategy with their employees. They are fostering their employees in terms of knowledge codification, attending public speaks and online training courses, and conducting internal team meetings and workshops. Furthermore, KFMC employees require social interaction media that supports the collaborative work from anywhere. The employees need something "handy", and easily set on their mobiles. Moreover, there is a need for knowledge base with advanced searching feature, hence, the KFMC employees can effectively utilize the codified knowledge.

\section{CONCLUSION}

This research contributes in discovering gatekeepers' practices in terms of gathering, collecting, and diffusing knowledge into their groups. Combining both the structure view and process view gives deep understanding of the context. The findings of this study highlight the gatekeepers bases and how they are collecting their knowledge using different technologies to serve their need [15]. Also, the results reveal that gatekeepers use different KS mechanisms, in order to share their knowledge with their colleagues [28]. The findings of this research assist managerial decision makers and strategic managers among start-up organizations and also wellstructured organizations in terms of policy, decision, and behavior creation. Therefore, they provide valuable insights and decisions in terms of policies, strategies, and the 
appropriate collaborative tools that foster the collaborative environment in the organizations. In such cases, employees can get faster answers for "What if?" and "How to do?" questions. Furthermore, applying this research in the local area and driving results directly from the practical environment gives evidences of strong outcomes in KM field.

The limitation of this study occurs in the area of using static SNA. The results might change when applying dynamic SNA.

\section{REFERENCES}

[1] Grant, R. M. (1996). Toward a knowledge-based theory of the firm. Strategic Management Journal, 17(52), 109-122. Retrieved from http://search.proquest.com/docview/225006502?accountid=142908.

[2] Alavi, M., \& Leidner, D. E. (2001). Review: knowledge management and knowledge management systems: Conceptual foundations and research issues. MIS Quarterly, 25(1),107-136. DOI: 10.2307/3250961.

[3] Nonaka, I. (1994). A dynamic theory of organizational knowledge creation. Organization Science, 5(1),14 - 37. Retrieved from http://dx.doi.org/10.1287/orsc.5.1.14.

[4] Chetty, L., \& Mearns, M. (2012). Using communities of practice towards the next level of knowledge-management maturity. SA Journal of Information Management, 14(1), 9-pages. DOI: 10.4102/sajim.v14i1.503.

[5] Noruzy, A., Dalfard, V. M., Azhdari, B., Nazari-Shirkouhi, S., \& Rezazadeh, A. (2013). Relations between transformational leadership, organizational learning, knowledge management, organizational innovation, and organizational performance: An empirical investigation of manufacturing firms. The International Journal of Advanced Manufacturing Technology, 64(5-8), 1073-1085. DOI: 10.1007/s00170012-4038-y.

[6] Stovel, K., \& Shaw, L. (2012). Brokerage. Annual Review of Sociology, 38, 139-158. DOI: 10.1146/annurev-soc-081309-150054.

[7] Cross, R., Borgatti, S. P., \& Parker, A. (2002). Making invisible work visible: Using social network analysis to support strategic collaboration. California Management Review, 44(2), 25-46. DOI: 10.2307/41166121.

[8] Allen, J., James, A. D., \& Gamlen, P. (2007). Formal versus informal knowledge networks in R\&D: A case study using social network analysis. $R \& D$ Management, 37(3), 179-196. DOI: $10.1111 / \mathrm{j} .1467-$ 9310.2007.00468.x

[9] Haythornthwaite, C. (1996). Social network analysis: An approach and technique for the study of information exchange. Library \& Information Science Research, 18(4), 323-342. Retrieved from https://doi.org/10.1016/S0740-8188(96)90003-1.

[10] Burt, R. S. (2000). The network structure of social capital. Research in Organizational Behavior, 22, 345-423. DOI: 10.1016/S01913085(00)22009-1.

[11] Burt, R. S. (2009). Structural holes: The social structure of competition. Harvard university press.

[12] Burt, R. S. (2005). Brokerage and closure: An introduction to social capital. OUP Oxford.

[13] Gould, R. V., \& Fernandez, R. M. (1989). Structure of mediation: A formal approach to brokerage in transaction networks. Sociological Methodology, 19, 89-126.DOI: 10.2307/270949.

[14] Tushman, M. L., \& Katz, R. (1980). External communication and project performance: An investigation into the role of gatekeepers. Management Science, 26(11), 1071-1085. Retrieved From http://www.jstor.org/stable/2631174.

[15] Barzilai-Nahon, K. (2008). Toward a theory of network gatekeeping: A framework for exploring information control. Journal of the American Society for Information Science and Technology, 59(9), 1493-1512. DOI: 10.1002/asi.20857.

[16] Haas, A. (2015). Crowding at the frontier: Boundary spanners, gatekeepers and knowledge brokers. Journal of Knowledge Management, 19(5), 1029-1047.Retrieved from http://www.emeraldinsight.com/doi/abs/10.1108/JKM-01-2015-0036.

[17] Migdadi, M. (2009). Knowledge management enablers and outcomes in the small-and-medium sized enterprises. Industrial Management \& Data
Systems, 109(6), 840-858. Retrieved from https://doi.org/10.1108/02635570910968072.

[18] AlAdaileh, R. M., \& AlAtawi, M. S. (2011). Organizational culture impact on knowledge exchange: Saudi telecom context. Journal of Knowledge Management, 15(2), 212-230. DOI: $10.1108 / 13673271111119664$.

[19] AlRowaily, K., \& Alsadhan, A. O. (2012). Integration of knowledge management system in telecommunication: A case study of Saudi telecom. International Journal of Computer Science and Network Security (IJCSNS), 12(11), 42-53. Retrieved from http://search.proquest.com/docview/1266373652?accountid=142908.

[20] AlAtawi, F. M., Williams, M. D., \& Dwivedi, Y. K. (2013). Exploring importance of environmental factors for adoption of knowledge management systems in Saudi Arabian public sector organizations. International Journal of Electronic Government Research (IJEGR), 9(4), 19-37. DOI: 10.4018/IJEGR.

[21] AlHarbi, J., \& Singh, S. (2013). Knowledge transfer, controls, and performance of MNE subsidiaries in the Kingdom of Saudi Arabia. Foresight, 15(4), 294-306. DOI: 10.1108/FS-04-2012-0021.

[22] AlAama, A. Y. (2014). Technology knowledge management (TKM) taxonomy. VINE, 44(1), 2-21. Retrieved from http://dx.doi.org/10.1108/VINE-12-2012-0052.

[23] Amir, R., \& Parvar, J. (2014). Harnessing knowledge management to improve organizational performance. International Journal of Trade, Economics \& Finance, 5(1). DOI: 10.7763/IJTEF.2014.V5.336.

[24] Elaimi, K., \& Persaud, A. (2014). The impact of organizational factors and Web 2.0 technologies on knowledge sharing in Saudi Arabian firms. The Journal of Human Resource and Adult Learning, 10(2), 30-40. Retrieved http://search.proquest.com/docview/1658777421 ?accountid=142908.

[25] Dulayami, S. T. H., \& Robinson, L. (2015). The individual and the collective. Journal of Documentation, 71(1), 198-209. DOI: 10.1108/JD-09-2014-0121.

[26] Dalkir, K. (2013). Knowledge Management in Theory and Practice. Cambridge: MIT Press.

[27] Cummings, J. N. (2004). Work groups, structural diversity, and knowledge sharing in a global organization. Management Science, 50(3), 352-364. Retrieved from http://search.proquest.com/docview/213169632?accountid=142908.

[28] Berends, H., Bij, H., Debackere, K., \& Weggeman, M. (2006). Knowledge sharing mechanisms in industrial research. R\&D Management, 36(1), 85-95. DOI: 10.1111/j.1467-9310.2005.00417.x.

[29] Grippa, F., Romano, A., \& Laubacher, R. (2007). Setting Up a Dashboard for Measuring Knowledge Flows: a Social Network-Based Methodology. eBMS-SS ISUFI-University of Lecce.

[30] Nahapiet, J., \& Ghoshal, S. (1998). Social capital, intellectual capital, and the organizational advantage. Academy of Management Review, 23(2), 242-266. Retrieved from http://www.jstor.org/stable/259373.

[31] Hau, Y. S., Kim, B., Lee, H., \& Kim, Y.-G. (2013). The effects of individual motivations and social capital on employees' tacit and explicit knowledge sharing intentions. International Journal of Information Management, 33(2), 356-366. Retrieved from http://dx.doi.org/10.1016/j.ijinfomgt.2012.10.009.

[32] Yue, H. (2012). Social network analyses on knowledge diffusion of China's management science. In F. Wang, J. Lei, Z. Gong, \& X. Luo (Eds.), Web Information Systems and Mining (Vol. 7529, pp. 117-124). Springer Berlin Heidelberg. Retrieved from http://dx.doi.org/10.1007/978-3-642-33469-6_17.

[33] Pujol, J. M., Sangüesa, R., \& Delgado, J. (2002). Extracting reputation in multi agent systems by means of social network topology (pp. 467474). Presented at the Proceedings of the First International Joint Conference on Autonomous Agents and Multiagent Systems: Part 1, Bolonga, Italy. ACM.

[34] Nieves, J., \& Osorio, J. (2013). The role of social networks in knowledge creation. Knowledge Management Research \& Practice, 11(1), 62-77. Retrieved from https://doi.org/10.1057/kmrp.2012.28.

[35] Mischen, P. A., \& Jackson, S. K. (2008). Connecting the dots: Applying complexity theory, knowledge management and social network analysis to policy implementation. Public Administration Quarterly, 32(3), 314- 
338.

Retrieved

http://search.proquest.com/docview/226968310?accountid=142908.

[36] Grippa, F., Palazzolo, M., Bucuvalas, J. C., \& Gloor, P. A. (2012). Supporting development efforts of clinical care teams. International Journal of Organizational Design and Engineering, 2(2), 149-166. DOI: 10.1504/IJODE.2012.047572.

[37] Breiger, R. L. (2004). The analysis of social networks (pp. 505-526).in handbook of data analysis edited by Hardy M., \& Bryman A., London: Sage.

[38] Curran, K., \& Curran, N. (2014). Social networking analysis. In N Bessis \& C. Dobre (Eds.), Big Data and Internet of Things: A Roadmap for Smart Environments (Vol. 546, pp. 367-378). Springer International Publishing. DOI: 10.1007/978-3-319-05029-4_15.

[39] Freeman, L. C. (1979). Centrality in social networks conceptual clarification. Social Networks, 1(3), 215-239. Retrieved from http://dx.doi.org/10.1016/0378-8733(78)90021-7.

[40] Freeman, L. C., Borgatti, S. P., \& White, D. R. (1991). Centrality in valued graphs: A measure of betweenness based on network flow. Social Networks, 13(2), 141-154. Retrieved from https://doi.org/10.1016/03788733(91)90017-N.

[41] Allen, T. J. (1969). Roles in technical communication networks. Massachusetts: Library of the Massachusetts of Technology.

[42] Allen, T. J., \& Cooney, S. (1973). Institutional roles in technology transfer: A diagnosis of the situation in one small country. $R \& D$ Management, 4(1), 41-51. DOI: 10.1111/j.1467-9310.1973.tb01030.x.

[43] Katz, R., \& Tushman, M. (1981). An investigation into the managerial roles and career paths of gatekeepers and project supervisors in a major R\&D facility. R\&D Management, 11(3), 103-110. DOI: 10.1111/j.14679310.1981.tb00458.x.

[44] Allen, T. J., Tushman, M. L., \& Lee, D. M. (1979). Technology transfer as a function of position in the spectrum from research through development to technical services. Academy of Management Journal, 22(4), 694-708. Retrieved from http://www.jstor.org/stable/255809.

[45] Cohen, W. M., \& Levinthal, D. A. (1990). Absorptive capacity: A new perspective on learning and innovation. Administrative Science Quarterly, 35(1), 128-152. DOI: 10.2307/2393553.

[46] Ettlie, J. E., \& Elsenbach, J. M. (2007). The changing role of R\&D gatekeepers. Research-Technology Management, 50(5), 59-66. Retrieved from http://www.tandfonline.com/doi/abs/10.1080/08956308.2007.1165746

[47] Aldrich, H., \& Herker, D. (1977). Boundary spanning roles and organization structure. Academy of Management Review, 2(2), 217230. Retrieved from http://www.jstor.org/stable/257905.

[48] Shoemaker, P. J., \& Vos, T. (2009). Gatekeeping theory. New York: Routledge.
[49] Olsen, P. I., Prenkert, F., Hoholm, T., \& Harrison, D. (2014). The dynamics of networked power in a concentrated business network. Journal of Business Research, 67(12), 2579-2589. Retrieved from http://dx.doi.org/10.1016/j.jbusres.2014.03.017.

[50] Gao, H., Knight, J. G., Yang, Z., \& Ballantyne, D. (2014). Toward a gatekeeping perspective of insider-outsider relationship development in China. Journal of World Business, 49(3), 312-320. DOI: 10.1016/j.jwb.2013.06.002.

[51] Mitchell, R., Boyle, B., Burgess, J., \& McNeil, K. (2014). "You can't make a good wine without a few beers": Gatekeepers and knowledge flow in industrial districts. Journal of Business Research, 67(10), 21982206. Retrieved from https://doi.org/10.1016/j.jbusres.2014.01.007

[52] Schiffauerova, A., \& Beaudry, C. (2012). Collaboration spaces in Canadian biotechnology: A search for gatekeepers. Journal of Engineering and Technology Management, 29(2), 281-306. Retrieved from https://doi.org/10.1016/j.jengtecman.2012.03.004.

[53] Yli-Renko, H., Autio, E., \& Sapienza, H. J. (2001). Social capital, knowledge acquisition, and knowledge exploitation in young technology - based firms. Strategic Management Journal, 22(6 - 7), 587-613. DOI: 10.1002/smj.183.

[54] Lee, H.-S., Lee, S.-H., \& Han, J. T. (2013). Social networks and knowledge management. International Journal of Digital Content Technology and Its Applications, 7(12), 307-312. Retrieved from http://search.proquest.com/docview/1546006794?accountid=142908.

[55] Elo, S., \& Kyngäs, H. (2008). The qualitative content analysis process. Journal of Advanced Nursing, 62(1), 107-115. DOI: 10.1111/j.13652648.2007.04569.x.

[56] Zhao, R., \& Chen, B. (2013). Study on enterprise knowledge sharing in ESN perspective: A Chinese case study. Journal of Knowledge Management, 17(3), 416-434. Retrieved from https://doi.org/10.1108/JKM-12-2012-0375.

[57] Behrendt, S., Richter, A., \& Trier, M. (2014). Mixed methods analysis of enterprise social networks. Computer Networks, 75, 560-577. DOI: 10.1016/j.comnet.2014.08.025.

[58] Edwards, G. (2010). Mixed-method approaches to social network Analysis. Discussion Paper. NCRM. Retrieved from http://eprints.ncrm.ac.uk/842/.

[59] Christensen, L., Johnson, R. B., \& Turner, L. (2013). Research Methods, Design, and Analysis (12th ed.). Pearson.

[60] Wang, Z., \& Wang, N. (2012). Knowledge sharing, innovation and firm performance. Expert Systems with Applications, 39(10), 8899-8908. Retrieved from http://dx.doi.org/10.1016/j.eswa.2012.02.017.

[61] Borgatti, S. P. (2005). Centrality and network flow. Social Networks, 27(1), 55-71. Retrieved from http://dx.doi.org/10.1016/j.socnet.2004.11.008. 